\title{
Late effects of cutaneous 3-methylcholanthrene exposure on DNA damage-related pleiotropic growth factors and oxidative stress markers in mice
}

\author{
Devrim $\mathrm{T}^{1}$, Ekici $\mathrm{H}^{2}$, Devrim $\mathrm{AK}^{3}$, Sozmen $\mathrm{M}^{4}$, Senol $\mathrm{A}^{3}$, Bozkurt KK $\mathrm{KK}^{5}$, Duru $\mathrm{O}^{3}$, Yalcin $\mathrm{S}^{6}$ \\ Department of Pathology, Faculty of Medicine, Kirikkale University, Kirikkale, Turkey. \\ tubadevrim@gmail.com
}

\begin{abstract}
BACKGROUND: Skin is the body's first defence against direct exposure to variety of chemicals. Polycyclic aromatic hydrocarbons such as 3-methylcholanthrene (3-MC) are common in polluted urban air and have a potential of producing harmful effects. Moreover, their late effects can occur months or years after exposure. OBJECTIVES: We aimed to investigate the long-term effects of 3-MC induced dermal toxicity on the expression of markers of apoptosis, pleiotropic cytokines, and oxidative stress and to determine the protective effect of cisplatin.

METHODS: Groups were designed as control (group 1), 3-MC applied (group 2) and 3-MC+cisplatin applied mice (group 3). Cutaneous expressions of TGF $\beta$, PDGFA, PDGFC, bFGF, PDGFRa, USP28, and Ki67 were evaluated with qPCR. Total oxidant (TOS), total antioxidant (TAS) and oxidative stress index (OSI) values were determined in liver and kidney tissues.

RESULTS: The expression levels of TGF $\beta$, PDGFRa, USP-28, Ki67, and PDGFA were decreased significantly in MC applied groups. Renal TAS levels were significantly lower in group-3. Liver and kidney OSI values were increased in both groups 2 and 3.

CONCLUSION: The results indicated that low dose 3-MC caused oxidative stress and downregulated apoptotic and cytokine markers in the long term and cisplatin had no ameliorative effects on this degeneration processes (Tab. 3, Fig. 3, Ref. 32). Text in PDF www.elis.sk.

KEY WORDS: 3-methylcholanthrene, late effect, oxidative stress, polycyclic aromatic hydrocarbons, pleiotropic cytokines.
\end{abstract}

\section{Introduction}

Reactive oxygen species are produced by living beings as an outcome of normal cellular metabolism and environmental agents, such as air pollutants or cigarette smoke (1). Polycyclic aromatic hydrocarbons such as 3-methylcholanthrene (3-MC) are common in polluted urban air and cause untoward effects including toxicity and carcinogenesis (2, 3). 3-MC induced applications

${ }^{1}$ Department of Medical Pathology, Kirikkale University School of Medicine, Kirikkale, Turkey, ${ }^{2}$ Department of Pharmacology and Toxicology, Kirikkale University Faculty of Veterinary Medicine, Kirikkale, Turkey, ${ }^{3}$ Department of Biochemistry, Kirikkale University Faculty of Veterinary Medicine, Kirikkale, Turkey, ${ }^{4}$ Department of Pathology, Ondokuz Mayis University Faculty of Veterinary Medicine, Samsun, Turkey, ${ }^{5}$ Department of Medical Pathology, Süleyman Demirel University School of Medicine, Isparta, Turkey and ${ }^{6}$ Department of Oncology, Kirikkale University School of Medicine, Kirikkale, Turkey.

Address for correspondence: T. Devrim, MD, Department of Pathology, Faculty of Medicine, Kirikkale University, 71450 Kirikkale, Turkey. Phone: +905432022088, Fax: +903183573301

Acknowledgements: This study was supported by The Scientific Research Projects Coordination Unit of Kirikkale University (Project code: 2019/030). have been used conventionally for determining immunosurveillance of tumorigenesis (4). The skin is the main natural cover for the body and, as the result of its direct exposure to variety of chemicals, it is at a considerable risk of developing harmful effects to the organs and late effects can occur months or years after exposure (5).

Pleiotropic growth factors have wide tissue dispersion and play crucial roles during embryonic development, normal tissue homeostasis, and carcinogenesis. These factors have cytostatic activities on normal epithelial cells, however, through a tumour suppressor pathway, they are proposed as powerful pro-tumorigenic agents, acting to coordinate peri-tumoral angiogenesis, together with tumour cell migration, immune escape, and dissemination to metastatic sites (6).

Cisplatin is commonly used in cancer chemotherapy (7) and is suggested as a new therapeutic intervention of precancerous stages before the invasive stage begins (8). Here we aimed to evaluate the alterations of pleiotropic growth factors in the skin tissues and oxidative stress levels in the kidney and liver samples of single dose 3-MC induced dermal toxicity in mice after a long- term period. We also investigated the effect of cisplatin on the late effects of single and low dose 3-MC application. 
Tab. 1. Oligo-primer sequences used in the qPCR analyses of the present study.

\begin{tabular}{llc}
\hline Gene & Primers & Reference \\
$\begin{array}{l}\text { Transforming growth } \\
\text { factor beta (TGF } \beta)\end{array}$ & $\begin{array}{l}\text { F:ACTGCCGTACAACTCCAGTGAC } \\
\text { R: CAACGCCATCTATGAGAAAACC }\end{array}$ & Nan et al (12) \\
\hline $\begin{array}{l}\text { Platelet-derived growth } \\
\text { factor A (PDGFA) }\end{array}$ & $\begin{array}{l}\text { F:CCTGTGCCCATCCGCAGGAAGAGA } \\
\text { R: TTGGCCACCTTGACGCTGCGGTG }\end{array}$ & Jin et al (13) \\
\hline $\begin{array}{l}\text { Platelet-derived growth } \\
\text { factor C (PDGFC) }\end{array}$ & $\begin{array}{l}\text { F: ACCACGAGTCCTTCGGTGTT } \\
\text { R: GCATTGTTGAGCAGGTCCAA }\end{array}$ & $\begin{array}{c}\text { di Tomaso et al } \\
\text { (14) }\end{array}$ \\
\hline $\begin{array}{l}\text { Basic fibroblast growth } \\
\text { factor (bFGF) }\end{array}$ & $\begin{array}{l}\text { F: GAAACACTCTTCTGTAACACACTT } \\
\text { R: GTCAAACTACAACTCCAAGCAG }\end{array}$ & \multirow{2}{*}{ Du et al (15) } \\
\hline $\begin{array}{l}\text { Platelet-derived growth factor } \\
\text { receptor } \alpha \text { (PDGFR } \alpha)\end{array}$ & $\begin{array}{l}\text { F: CGACTCCAGATGGGAGTTCCC } \\
\text { R: TGCCATCCACTTCACAGGCA }\end{array}$ & Gonzalez et al (16) \\
$\begin{array}{l}\text { Ubiquitin specific } \\
\text { peptidase 28 (USP28) }\end{array}$ & $\begin{array}{l}\text { F:ACTCAGACTATTGAACAGATGTACTGC } \\
\text { R: CTG CATGCAAGCGATAAGG }\end{array}$ & Saei et al (17) \\
\hline Ki67 & $\begin{array}{l}\text { F: AATCCAACTCAAGTAAACGGGG } \\
\text { R: TTGGCTTGCTTCCATCCTCA }\end{array}$ & Sobecki et al (18) \\
\hline GAPDH & $\begin{array}{l}\text { F: CTGGGATGGAAATTGTGAGG } \\
\text { R: TGGCCTCCAAGGAGTAAGAA }\end{array}$ & Sonobe et al (19) \\
\hline
\end{tabular}

Histopathological evaluation of skin tissues

Tissues were collected from mice at necropsy and fixed in formalin, followed by embedding in paraffin wax. After that, sections of about $5 \mathrm{~mm}$ thick were stained with haematoxylin and eosin (H\&E). The H\&E stained slides of the skin samples were evaluated histopathologically.

\section{Biochemical analysis}

Kidney and liver tissues were washed with saline at $+4{ }^{\circ} \mathrm{C}$, dried on blotting paper and stored in $1 \mathrm{ml}$ storage vials and stored in deep freezer $\left(-80^{\circ} \mathrm{C}\right)$ until analyses were performed. Before the analyses, renal and liver tissues were homogenized using a homogenizer (Stuart, SHM1/EURO, UK) by adding $(10 \%, \mathrm{w} / \mathrm{v}) 140 \mathrm{mM} \mathrm{KCl}$ solution at

\section{Materials and methods}

Animals and husbandry

The study design was approved by the Animal Experiments Local Ethics Committee (Decision no. 2018/47). A total of 30 male, 10 weeks old BALB/c mice (Kobay Inc, TR) weighing $30 \pm 3.59$ g were randomly divided into three groups, each consisting of 10 mice. The conditions of the cage environment, care, and feeding of the animals were designed as previously reported (9).

\section{Experimental design and treatment of animals}

The study groups were designed as the healthy control group (group 1), 3-methylcholanthrene (3-MC) applied group (group 2) and the 3-MC and cisplatin applied group (group 3). At the beginning of the study, a single intradermal (i.d.) injection of $15 \mathrm{mg} /$ kg 3-MC (213942, Sigma-Aldrich, Germany) dissolved in $0.1 \mathrm{ml}$ sesame oil was performed to the interscapular skin of group- 2 and group-3 mice. After a six months period, $10 \mathrm{mg} / \mathrm{kg}$ intraperitoneal cisplatin (Sigma-Aldrich, Germany) was injected in the group-3 mice. Group-1 injections were performed with saline in the same way. The mice were euthanized by an exposure to gradually increasing concentrations of carbon dioxide $\left(\mathrm{CO}_{2}\right)$ two weeks after the cisplatin injection.
$+4{ }^{\circ} \mathrm{C}(10)$. The obtained homogenates were centrifuged at 3000 rpm for 5 minutes at $+4{ }^{\circ} \mathrm{C}$. Oxidative stress parameters were measured in supernatants formed after a centrifugation (9). The levels of Total Antioxidant Status (TAS) and Total Oxidant Status (TOS) in liver and kidney tissue homogenates were measured spectrophotometrically (MultiskanGO, Thermo, USA) using the methods described in the kits (Rel Assay Kit Diagnostics, TR). Results were expressed in mmol Trolox equiv./lt for TAS and $\mu \mathrm{mol} \mathrm{H}_{2} \mathrm{O}_{2}$ equiv./lt for TOS (9). In addition, the oxidative stress index (OSI), expressed as a percentage of the ratio of TOS levels to TAS levels, was also calculated and the results were expressed in the arbitrary unit (AU) (10).

\section{Quantitative Real-Time PCR}

Total RNA was isolated from sampled skin tissues using the total RNA isolation kit (74106, QIAGEN, Venlo, The Netherlands). The concentration and purity values of obtained total RNA samples were evaluated by determining the absorbance at 260 and 280 $\mathrm{nm}$ using a nanodrop spectrophotometer (MultiskanGO, Thermo Scientific, Vantaa, Uusimaa, Finland) and calculating A260/A280 ratio. cDNA samples were synthesized using a commercial kit (K1671, Vantaa, Uusimaa, Finland) and each of them was quantified to $200 \mathrm{ng}$ and used for amplifying the investigated genes using a quantitative real-time PCR (qPCR) reactions.
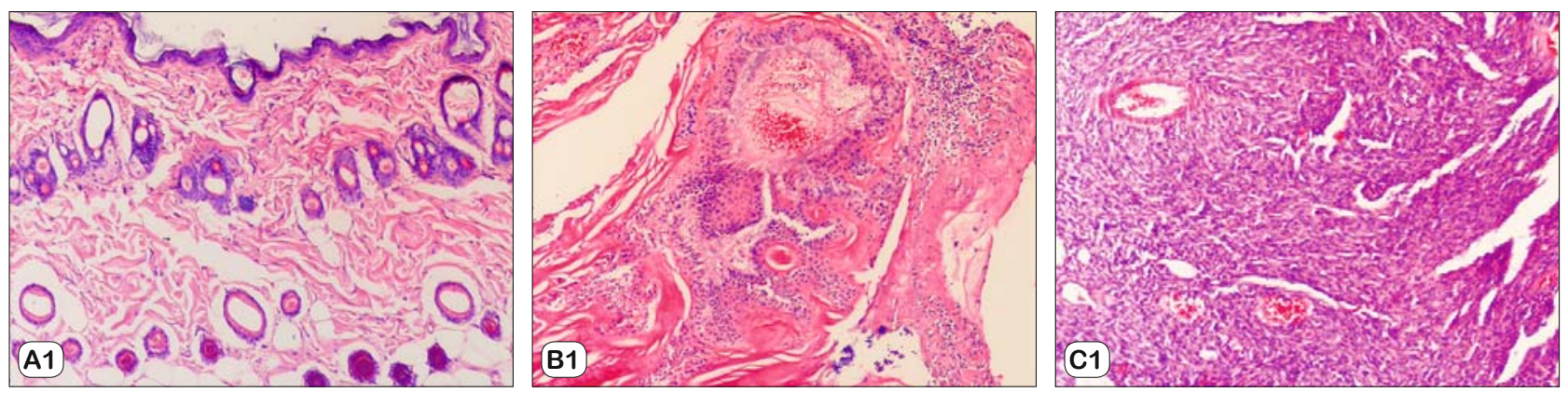

Fig. 1. Hematoxylin and Eosin Stained sections. A1: Normal skin tissue (x100), B1: Squamous cell carcinoma (x100), and C1: Fibrosarcoma (x100). 
Tab. 2. Levels of oxidative stress markers in kidney and liver tissues.

\begin{tabular}{|c|c|c|c|c|c|}
\hline & \multicolumn{3}{|c|}{ Groups } & \multirow{2}{*}{$\mathrm{p}$} \\
\hline & & Control & 3-MC & 3-MC+Cisplatin & \\
\hline \multirow{3}{*}{ Kidney } & $\begin{array}{l}\text { TAS } \\
\text { (mmol Trolox equiv./l) }\end{array}$ & $0.92 \pm 0.078$ & $0.73 \pm 0.03$ & $0.68 \pm 0.02$ & 0.03 \\
\hline & $\begin{array}{l}\text { TOS } \\
\left(\mu \mathrm{mol} \mathrm{H}_{2} \mathrm{O}_{2} \text { equiv./l) }\right.\end{array}$ & $7.10 \pm 0.89$ & $8.85 \pm 0.72$ & $9.56 \pm 1.14$ & $>0.05$ \\
\hline & $\begin{array}{l}\text { OSI } \\
(\mathrm{AU})\end{array}$ & $0.78 \pm 0.08$ & $1.22 \pm 0.10$ & $1.42 \pm 0.18$ & $<0.01$ \\
\hline \multirow{3}{*}{ Liver } & $\begin{array}{l}\text { TAS } \\
\text { (mmol Trolox equiv./l) }\end{array}$ & $1.52 \pm 0.06$ & $1.49 \pm 0.05$ & $1.44 \pm 0.03$ & $>0.05$ \\
\hline & $\begin{array}{l}\text { TOS } \\
\left(\mu \mathrm{mol} \mathrm{H}_{2} \mathrm{O}_{2} \text { equiv./l) }\right.\end{array}$ & $8.07 \pm 0.68$ & $10.38 \pm 0.55$ & $9.87 \pm 0.49$ & $>0.05$ \\
\hline & $\begin{array}{l}\text { OSI } \\
\text { (AU) }\end{array}$ & $0.53 \pm 0.03$ & $0.71 \pm 0.05$ & $0.68 \pm 0.03$ & 0.01 \\
\hline
\end{tabular}

3-MC: 3-methylcholanthrene, TAS: Total Antioxidant Status, TOS: Total Oxidant Status, OSI: Oxidative Stress Index. $\mathrm{p}<0.05$ was considered significant (Kruskal-Wallis). Data are presented as the mean \pm standard error (SE). dehydrogenase (GAPDH) as the housekeeping gene (Tab. 1). The obtained crossing point $(\mathrm{Cp})$ values were utilized to determine the relative expressions using the equation of $2^{-\Delta \Delta \mathrm{Ct}}(11)$.

\section{Statistical analyses}

Statistical analyses were performed by the Statistical Package for the Social Sciences (IBM, New York, USA). Differences of the expression values were evaluated by the Kruskal-Wallis test and Mann-Whitney U test. Data are presented as the mean \pm standard error (SE). $p$ values less than 0.05 were considered significant.
Amplifications were performed by a qPCR instrument (LightCycler ${ }^{\circledR} 480$ II, Roche, Mannheim, Baden-Württemberg, Germany) and its supply (SYBR Green I Master Kit, Roche). This way, the expressions of TGF $\beta$, PDGFA, PDGFC, bFGF, PDGFR $\alpha$, USP28, and Ki67 genes were normalized to glyceraldehyde 3-phosphate

\section{Results}

The skin tissues, with intradermally applied low dose 3-MC, were evaluated for tumour development. Fibrosarcoma (FSA) and squamous cell carcinoma (SCC) cases were detected at the appli-
Kidney

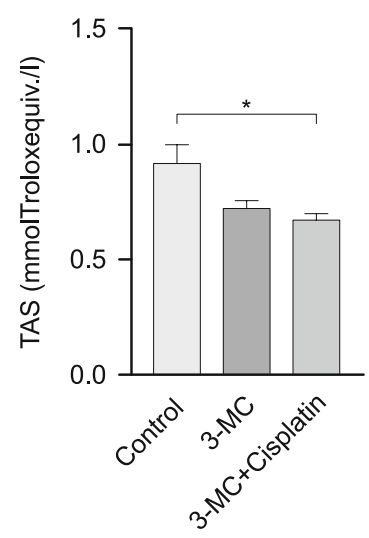

Liver

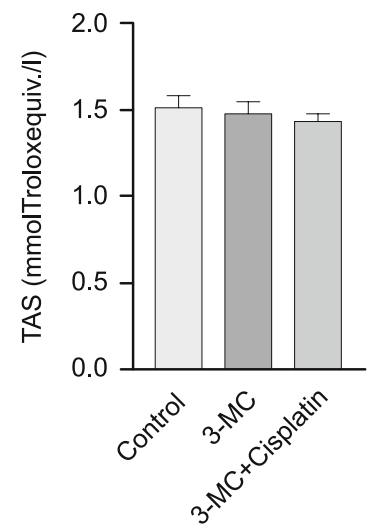

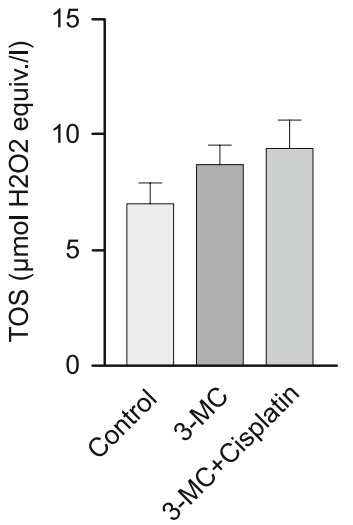
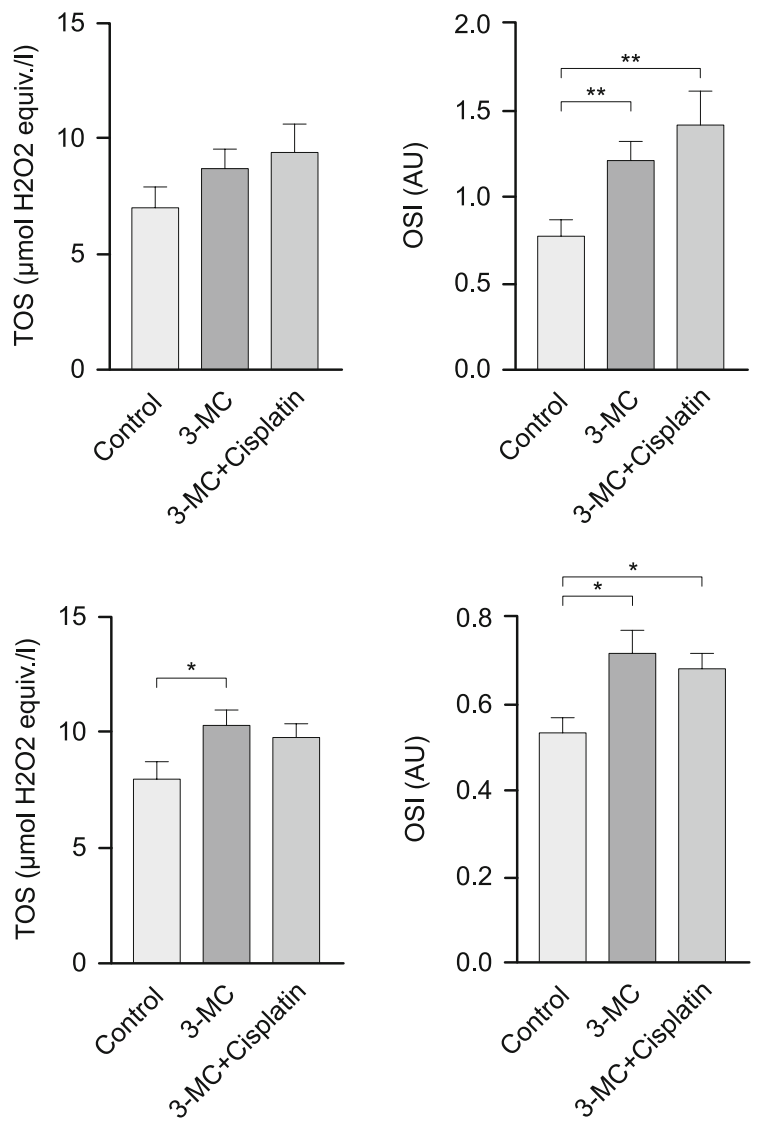

Fig. 2. Results of the oxidative stress markers in kidney and liver tissues in control, 3-MC applied and 3-MC+cisplatin applied study groups. Asterisks indicate significant $(*: p<0.05 ; * *: p<0.01)$ differences between the groups (Mann-Whitney $U$ test). Data are presented as the mean \pm standard error (SE). 


\section{$325-330$}

cation site of 3-MC in four mice. Tumours $>2 \mathrm{~mm}$ in diameter, and demonstrating progressive growth were recorded as positive (20). FSA and SCC cases were represented in Figure 1.

The levels of the oxidative stress markers in kidney and liver tissues are indicated in Table 2 . Renal TAS levels were significantly lower in group- 3 than in the controls $(\mathrm{p}<0.05)$. Liver and kidney OSI values were increased in both groups 2 and 3, compared to the controls $(p<0.05)$. No significant alterations were observed between the values of the groups 2 and 3 . The levels of renal OSI $(p<0.01)$, liver TOS $(p<0.05)$, and liver OSI $(p=0.01)$ were increased significantly in the group 2 compared to the controls. Renal $(\mathrm{p}<0.01)$ and liver OSI $(\mathrm{p}<0.05)$ values were increased significantly in the group 3 compared to the controls. However, the levels of renal TAS $(p=0.01)$ were decreased in the group-3 compared to the controls (Fig. 2).

\section{qPCR results}

TGF $\beta$, PDGFR $\alpha$, USP-28, and Ki67 genes were decreased significantly (Kruskal-Wallis test, $\mathrm{p}$ all $<0.05$ ) in the groups 2 and 3, compared to the controls (Tab. 3). Further, the difference
Tab. 3. Levels of relative gene expressions in skin tissues.

\begin{tabular}{lcccc}
\hline & \multicolumn{3}{c}{ Groups } & $\mathrm{p}$ \\
\cline { 2 - 4 } Genes & Control & 3-MC & 3-MC+Cisplatin & \\
\hline TGF $\beta$ & $1.46 \pm 0.36$ & $1.03 \pm 0.34$ & $0.66 \pm 0.18$ & 0.03 \\
PDGFA & $1.14 \pm 0.18$ & $1.23 \pm 0.47$ & $1.05 \pm 0.47$ & $>0.05$ \\
PDGFC & $56.87 \pm 15.07$ & $53.83 \pm 18.62$ & $21.55 \pm 4.67$ & $>0.05$ \\
bFGF & $10.58 \pm 3.82$ & $14.45 \pm 4.61$ & $6.24 \pm 2.36$ & $>0.05$ \\
PDGFR $\alpha$ & $2.30 \pm 0.79$ & $0.62 \pm 0.33$ & $0.10 \pm 0.05$ & 0.001 \\
USP-28 & $1.15 \pm 0.21$ & $0.25 \pm 0.11$ & $0.35 \pm 0.20$ & 0.04 \\
Ki67 & $1.38 \pm 0.28$ & $0.71 \pm 0.28$ & $0.89 \pm 0.27$ & 0.03 \\
\hline
\end{tabular}

3-MC: 3-methylcholanthrene, $\mathrm{p}<0.05$ was considered significant (Kruskal-Wallis test). Data are presented as the mean \pm standard error (SE)

between the groups was evaluated by the Mann-Whitney U test. The expression levels of Ki67 ( $p=0.01)$ USP28 ( $p=0.02)$, TGF $\beta$ $(\mathrm{p}<0.05)$, and PDGFR $\alpha(\mathrm{p}<0.01)$ were decreased significantly in the group 2 compared to the controls. Also, the expression levels of Ki67 (p<0.05), USP28 (p<0.05), TGF $\beta(p=0.02)$, PDGFA $(\mathrm{p}<0.05)$ and PDGFR $\alpha(\mathrm{p}<0.01)$ were diminished significantly in the group-3 compared to the controls (Fig. 3).
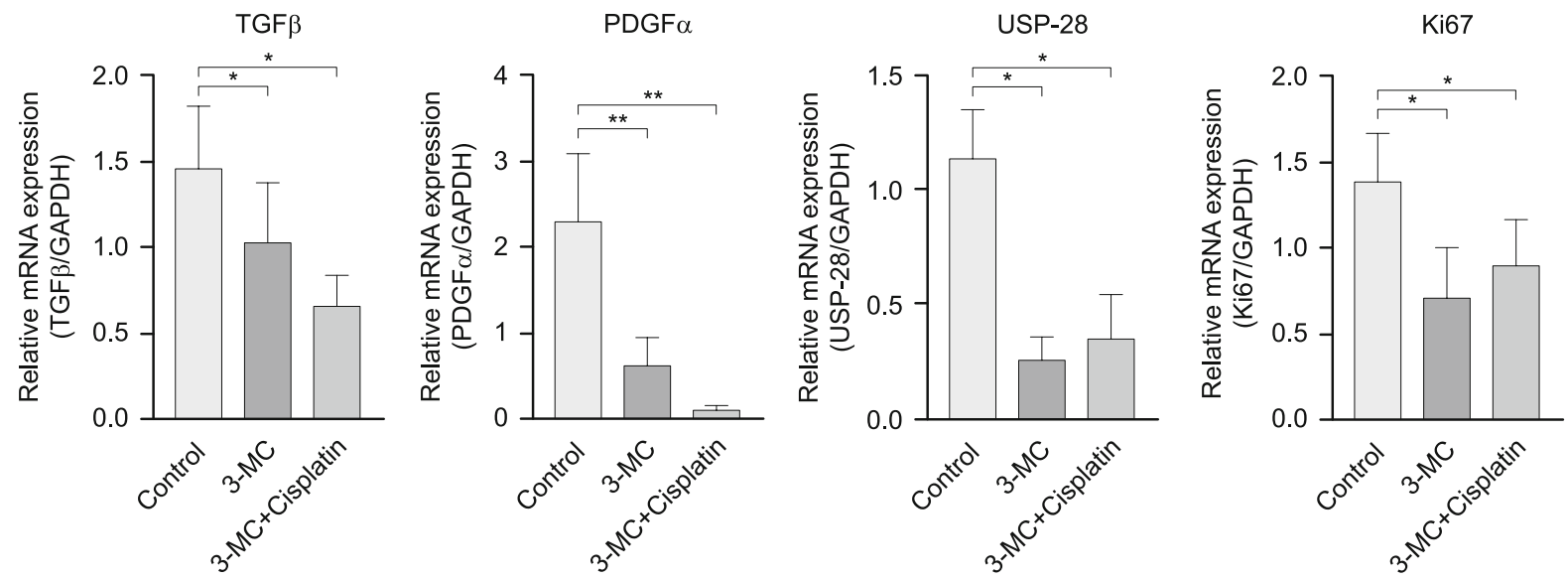

bFGF

PDGFA
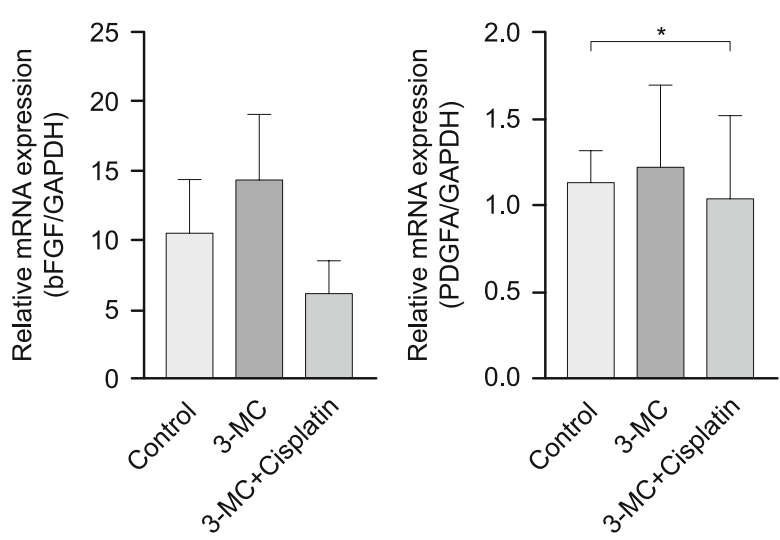

PDGFC

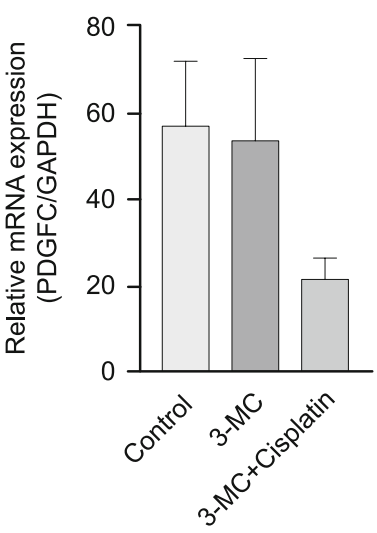

Fig. 3. Quantitative Real-Time PCR (qPCR) analysis results of the control, 3-MC applied and 3-MC+cisplatin applied study groups. Asterisks indicate significant $(*: \mathbf{p}<0.05 ; * *: \mathbf{p}<0.01)$ differences between the groups determined with Mann-Whitney $U$ test. Data are presented as the mean \pm standard error $(\mathrm{SE})$. 


\section{Discussion}

Here we investigated the late effects of a single and low dose (21) i.d. 3-MC application, a polycyclic aromatic hydrocarbon displaying carcinogenic activity, and cisplatin, a well-known chemotherapeutic drug, on the levels of pleiotropic cytokines as well as apoptosis and oxidative stress markers in mice. We found cytokinal and anti-apoptotic alterations among the experimental groups, as well as the formation of FSA and SCC in four 3-MC applied mice. We determined that applying a low dose and evaluating a long term 3-MC induction gave rise to a disruption in the levels of DNA damage-related pleiotropic growth factors and oxidative stress markers. To the best of our knowledge, the present study is the first in literature in terms of investigating the late effects of low dose 3-MC on the skin tissue.

Among DNA damage-related pleiotropic growth factors, TGF- $\beta$ plays an important role in maintaining tissue homeostasis (22). With its pro-apoptotic effect, it acts as a tumour suppressor, also suppressing epithelial cell proliferation and inflammatory response (23). A disruption of the TGF- $\beta$ signalling pathway is of great importance in cancer initiation and progression (24). In our study, we found a statistically significant decrease in TGF- $\beta$ expression levels in both 3-MC and 3-MC+cisplatin groups $(\mathrm{p}<0.05)$. In the study applying the same dose and administration of 3-MC, authors induce both SCC and FSA by a single i.d. injection of 3-MC (25). We also detected SCC and FSA in four cases of our study. Authors reported lower levels of TGF- $\beta$ in the mice with FSA than in the mice having SCC (25). In parallel with this finding, we found a 2-fold decrease in our FSA cases compared to the SCCs.

Platelet-derived growth factors (PDGFs) and the PDGF receptors have significant roles in improving connective tissue cells. PDGFR $\alpha$ signalling audits gastrulation and the improvement of varied organs like skin, lung, intestine, kidney, bones, and testis tissues (26). PDGFR $\alpha$ is frequently stated in the pathological conditions e.g. atherosclerosis, fibrosis, and cancer, probably reflective of a complicated process of the mesenchymal stem cell activity during pathogenesis (27). We found a significant downregulation in the expression of PDGFR $\alpha$ in the group- 2 and 3 by qPCR ( $<<0.05)$. Similar to our results, D'Arcangelo et al. (28) reported significantly reduced PDGFR $\alpha$ levels in melanoma biopsies. Authors suggested that PDGFR $\alpha$ strongly inhibits carcinogenesis and endothelium proliferation, and melanoma progression eliminates cells expressing PDGFR $\alpha$ (28). We consider the same perspective for 3-MC application and think that observed downregulations in the PDGFR $\alpha$ levels might have been due to its carcinogenic activity.

Ubiquitination is one of the most significant post-translational modifications and it enacts variable functions in cancer-related mechanisms. It also has functions in cell-cycle progression, apoptosis, and transcription (29). Adaptable reactions adjusting deubiquitinating enzyme (DUBs) activity has been shown to control signalling in a number of carcinogenic pathways (30). The Ubiquitin Specific Peptidase 28 (USP28) is a deubiquitinase playing important roles in the DNA damage pathway (31). USP28 fights against the activity of E3 ligases and antagonizes FBW7, an F-box protein and an important component of the E3 ubiquitin ligase aiming transcriptional agents to ubiquitin-directed proteasome degradation (29). We found significantly decreased USP28 gene expression levels in the group- 2 and 3 of the present study. Saei and Eichhorn (30) reported that skin showed subdued levels of USP28 and the enzymatic activity of USP28 was limited by FBW7 leading to the corruption of oncogenes. We think that suppressed USP28 levels in the skin tissues we examined might be based on the mechanism mentioned by the authors.

Comba et al (32) reported elevated levels of TOS and OSI by 3-MC administration. The authors performed their study in blood sera of intraperitoneally $25 \mathrm{mg} / \mathrm{kg} 3-\mathrm{MC}$ applied rats. The levels of the oxidative stress markers of the present study determined that intradermal 3-MC application caused oxidative stress in liver and kidney in the long term. Also, it was determined that cisplatin had no remedial effects on the oxidative tissue degeneration processes induced by 3-MC application in mice. Consequently, the present study proposed that hepatotoxicity and nephrotoxicity were important drawbacks of 3-MC as a late effect.

\section{Conclusion}

In conclusion, this paper discussed the assessment of the pathobiochemical effect of exposure to low doses of a carcinogen. Human skin is often exposed to chemicals at a low dose and presents their effects after a long period of time. This issue is of great significance both in the areas of occupational and environmental hazards. The present study proposed that late effects of 3-MCinduced toxigenicity could lead to oxidative stress in liver and kidney and the disruption of the immunoprotective mechanisms mediated by cytokines in the skin tissue.

\section{References}

1. Birben E, Sahiner UM, Sackesen C, Erzurum S, Kalayci O. Oxidative stress and antioxidant defense. World Allergy Organ J 2012; 5 (1): 9-19.

2. Gressani MK, Rollins LA, Kabler SL, Cline JM, Miller MS. Induction of mutations in ki-ras and Ink4a in liver tumors of mice exposed in utero to 3-methylcholanthrene. Carcinogenesis 1998; 19: 1045-1052.

3. Polat F, Dere E, Gül E, Yelkuvan I, Özdemir Ö, Bingöl G. The effect of 3-methylcholanthrene and butylated hydroxytoluene on glycogen levels of liver, muscle, testis, and tumor tissues of rats. Turk J Biol 2013; 37: 33-38.

4. Wakita D, Chamoto K, Ohkuri T et al. IFN- gamma-dependent type 1 immunity is crucial for immunosurveillance against squamous cell carcinoma in a novel mouse carcinogenesis model. Carcinogenesis 2009; 30: 1408-1415.

5. Rastogi S, Shukla Y, Paul BN, Chowdhuri DK, Khanna SK, Das M. Protective effect of Ocimum sanctum on 3-methylcholanthrene, 7,12-dimethylbenz(a)anthracene and aflatoxin B1 induced skin tumorigenesis in mice. Toxicol Appl Pharmacol 2007; 1224 (3): 228-240.

6. Perrot CY, Javelaud D, Mauviel A. Insights into the transforming growth factor- $\beta$ signaling pathway in cutaneous melanoma. Ann Dermatol 2013; 25(2): 135-144. 
7. Zarei S, Reza JZ, Jaliani HZ, Hajizadeh MR, Sargazi S, Hosseinian H. Effects of carfilzomib alone and in combination with cisplatin on the cell death in cisplatin-sensitive and cisplatin-resistant ovarian carcinoma cell lines. Bratisl Med J 2019; 120 (6): 468-475.

8. Abdul AB, Abdelwahab SI, Bin Jalinas J, Al-Zubairi AS, Taha MM. Combination of zerumbone and cisplatin to treat cervical intraepithelial neoplasia in female BALB/c mice. Int J Gynecol Cancer 2009; 19 (6): 1004-1010.

9. Devrim AK, Sozmen M, Devrim T, Sudagidan M, Cinar M, Kabak YB. Periostin normalizes levels of cardiac markers in rats with experimental isoproterenol cardiotoxicity. Bratisl Med J 2017; 118 (11): 705-709.

10. Sak S, Uyanikoglu H, Incebiyik A, Incebiyik H, Hilali NG, Sabuncu T, Sak E. 2018. Associations of serum fetuin-A and oxidative stress parameters with polycystic ovary syndrome. Clin Exp Reprod Med 45; 3: $116-121$.

11. Sözmen M, Devrim AK, Sudağidan M, Kabak YB, Beytut E, Özba B. Significance of angiogenic growth factors in bovine ocular squamous cell carcinoma. J Comp Pathol 2019; 170: 60-69.

12. Nan Y, Kong $\mathbf{L}$, Ren $\mathbf{W}$ et al. Activation of peroxisome proliferator activated receptor alpha ameliorates ethanol mediated liver fibrosis in mice. Lipids Health Dis 2013; 12: 10-11.

13. Jin S, Zhang M, Gao Y, Zhang X, Cui G, Zhang Y. The efficacy of Jing Wan Hong ointment for nerve injury diabetic foot ulcer and its mechanisms. J Diabetes Res 2014; 2014: 259412.

14. di Tomaso E, London N, Fuja D et al. PDGF-C induces maturation of blood vessels in a model of glioblastoma and attenuates the response to anti-VEGF treatment. PLoS One 2009; 4 (4): e5123.

15. Du W, Prochazka J, Prochazkova M, Klein OD. Expression of FGFs during early mouse tongue development. Gene Expr Patterns 2016; 20 (2): 81-87.

16. Gonzalez D, Contreras O, Rebolledo DL, Espinoza JP, van Zundert B, Brandan E. ALS skeletal muscle shows enhanced TGF- $\beta$ signaling, fibrosis and induction of fibro/adipogenic progenitor markers. PLoS One 2017; 12(5): e0177649

17. Saei A, Palafox M, Benoukraf T et al. Loss of USP28-mediated BRAF degradation drives resistance to RAF cancer therapies. J Exp Med 2018; 215 (7): 1913-1928.

18. Sobecki M, Mrouj K, Camasses A et al. The cell proliferation antigen Ki-67 organises heterochromatin. eLife 2016; 7 (5): e13722.

19. Sonobe A, Jesmin S, Shimojo $\mathbf{N}$ et al. Concomitant down-regulation of Et1-Etb system and VEGF angiogenic signaling in the frontal cortex of endotoximic mice: A heightened vulnerability to cerebral microcirculation in sepsis. J Vasc Med Surg 2015; 3: 206.
20. Swann JB, Vesely MD, Silva A, Sharkey J, Akira S, Schreiber RD, Smyth MJ. Demonstration of inflammation-induced cancer and cancer immunoediting during primary tumorigenesis. Proc Natl Acad Sci USA 2008; 15 (105): 652-656.

21. Takagi A, Matsuzaki T, Sato M, Nomoto K, Morotomi M, Yokokura T. Inhibitory effect of oral administration of Lactobacillus casei on 3-methylcholanthrene-induced carcinogenesis in mice. Med Microbiol Immunol 1999; 188 (3): 111-116.

22. Xu X, Zheng L, Yuan Q, Zhen G, Crane JL, Zhou X, Cao X. Transforming growth factor- $\beta$ in stem cells and tissue homeostasis. Bone Res 2018; (6) 2: 1-31.

23. Hao Y, Baker D, ten Dijke P. TGF- $\beta$-mediated epithelial-mesenchymal transition and cancer metastasis. Int J Mol Sci 2019; 20 (11): 2767.

24. Zhao M, Mishra L, Deng CX. The role of TGF- $\beta /$ SMAD4 signaling in cancer. Int J Biol Sci 2018; 14 (2): 111-123.

25. Chamoto K, Wakita D, Ohkuri T, Uchinami Y, Matsushima K, Kitamura H, Nishimura T. 3-Methylcholanthrene-induced transforming growth factor-beta-producing carcinomas, but not sarcomas, are refractory to regulatory T cell-depletion therapy. Cancer Sci 2010; 101 (4): 855-861.

26. Chen PH, Chen X, He X. Platelet-derived growth factors and their receptors: structural and functional perspectives. Biochim Biophys Acta 2013; 1834 (10): 2176-2186.

27. Farahani RM, Xaymardan M. platelet-derived growth factor receptor alpha as a marker of mesenchymal stem cells in development and stem cell biology. Stem Cells Int 2015; 2015: 362753.

28. D'Arcangelo D, Facchiano F, Nassa G et al. PDGFR-alpha inhibits melanoma growth via CXCL10/IP-10: a multi-omics approach. Oncotarget 2016; 227 (47): 77257-77275.

29. Wang X, Liu Z, Zhang L et al. Targeting deubiquitinase USP28 for cancer therapy. Cell Death Dis 2018; 9 (2): 186.

30. Saei A, Eichhorn PJA. Ubiquitination and adaptive responses to BRAF inhibitors in Melanoma. Mol Cell Oncol 2018; 5 (5): e1497862.

31. Devrim T, Ataç F, Devrim AK, Balci M. The concomitant use of USP28 and p53 to predict the progression of urothelial carcinoma of the bladder. Pathol Res Pract 2019; 2: 152774. doi: 10.1016/j. prp.2019.152774.

32. Comba B, Oto G, Mis L, Özdemir H. Comba A. Effects of borax on inflammation, haematological parameters and total oxidant-antioxidant status in rats applied 3-methylcholanthrene. Kafkas Univ Vet Fak Derg 2016; 22 (4): 539-544.
Received January 2, 2020. Accepted February 11, 2020. 